\title{
CORRECTION
}

\section{Correction to: Behavioral and psychological factors associated with suboptimal weight loss in post-bariatric surgery patients}

\author{
Marjolein M. Geerts ${ }^{1}$ (D) Elske M. van den Berg ${ }^{1}$ (D) Laura van Riel $^{1}$ (D) Jaap Peen ${ }^{2}$ (D) Anna E. Goudriaan ${ }^{1,3,4}$ (D) \\ Jack J. M. Dekker ${ }^{2}$ (D)
}

Published online: 23 June 2020

(c) Springer Nature Switzerland AG 2020

\section{Correction to: \\ Eating and Weight Disorders - Studies on Anorexia, Bulimia and Obesity https://doi.org/10.1007/s40519-020-00930-7}

Unfortunately, the 5th author name has been incorrectly published in the original publication. The complete correct name should read as following.

Anna E. Goudriaan

The original article has been updated.
Publisher's Note Springer Nature remains neutral with regard to jurisdictional claims in published maps and institutional affiliations.
The original article can be found online at https://doi.org/10.1007/ s40519-020-00930-7.

Marjolein M. Geerts

Marjolein.Geerts@novarum.nl

Elske M. van den Berg

Elske.vanden.Berg@Novarum.nl

Laura van Riel

Laura.van.Riel@Novarum.nl

Jaap Peen

Jaap.Peen@ Arkin.nl

Anna E. Goudriaan

Anneke.Goudriaan@Arkin.nl

Jack J. M. Dekker

Jack.Dekker@Arkin.nl
1 Novarum, Center for Eating Disorders and Obesity, Jacob Obrechtstraat 92, 1071 KR Amsterdam, The Netherlands

2 Arkin, Klaprozenweg 111, 1033 NN Amsterdam, The Netherlands

3 Department of Psychiatry, Amsterdam University Medical Center, University of Amsterdam, Amsterdam, The Netherlands

4 Amsterdam Institute for Addiction Research, Amsterdam, The Netherlands 